THE WABASH CENTER

JOURNAL ON TEACHING

\title{
Classroom Talk for Social Change: Critical Conversations in English Language Arts
}

\author{
Melissa Schieble, Amy Vetter, and Kahdeidra Monét Martin \\ New York, NY: Teachers College Press, 2020 (160 pages, ISBN 978-0-8077-6348-3, \\ \$34.95)
}

\author{
Reviewed By \\ Rachel Moquin \\ Union University
}

Critical conversations in the classroom can create space for processing complex societal issues and disparities that students will encounter in their lives. In Classroom Talk for Social Change: Critical Conversations in English Language Arts, Melissa Schieble, Amy Vetter, and Kahdeidra Monét Martin posit that these conversations aid students in developing their voice, increase student learning, and empower students to drive social change. In contrast to teacher-led discourse structures, like the monologic teaching method or Freire's banking model of education, fostering critical conversations empowers students as leaders and contributors in a shared classroom space. Through an analysis of six ELA classrooms across three years, readers experience firsthand practices, successes, failures, transcripts, and reflections from these classrooms. Each author brings a distinct viewpoint and background to the text, resulting in a thoughtful, sincere how-to manual for any teacher wishing to foster critical conversations with her students.

Highly readable, Classroom Talk has a clear organizational structure that aids in implementing this strategy in a classroom. The authors unpack what critical conversations are and how to confront dominant societal narratives regarding power and privilege. They then explain how to adopt a critical learner stance and create safe space for critical conversations, and discuss how to increase student learning and impact by providing tools for supporting meaning making during these discussions and sustaining dialogue through talk moves. The book ends with an example of how their focus teachers reflected on the critical conversations that took place in their classrooms via transcript analysis in inquiry groups.

One of the most powerful elements of this text is the clear breakdown of how to facilitate these conversations with students, paired with examples from classroom teachers. The authors include reader-friendly charts, graphics, and resources throughout. Classroom teachers will find the compiled list of literary works that lend themselves well to critical conversations extremely useful as they attempt to break from within the traditional literary canon to provide space for rich discussion. Additional useful tools include sample discussion question frames, guiding questions for critical selfreflection, characteristics of critical conversations, a breakdown of critical talk moves, and a list of specific practices for supporting meaning making during discussion.

The intended audience for this text is K-12 ELA classroom teachers, but it also has direct applicability to those faculty charged with training future ELA teachers or any faculty interested in engaging their students in critical conversations. This text lays out the why and how of engaging students in these critical conversations, which would be of value to nearly any discussion-based course in any field. The authors also showcase the power of inquiry groups as a tool to study one's own practice and reflect with others in a collaborative setting.

By doing what the authors ask in "reflecting on knowing what you don't know" (122) and following the processes they have laid out for approaching critical conversations, reflecting on them via transcript analysis with colleagues, and seeking additional resources, faculty and educators can approach this powerful learning tool with greater confidence. 